\title{
Parameters affecting chain elongation from syngas bioconversion
}

\author{
Carla Fernández Blanco, Haris N. Abubackar, María C. Veiga \\ and Christian Kennes*
}

*Kennes@udc.es

University of La Coruña, BIOENGIN group, Faculty of Sciences and Center for Advanced Scientific Research (CICA), E-15008-La Coruña, Spain

\section{HIGHLIGHTS:}

- Chain elongation in C. kluyveri is optimal at near neutral $\mathrm{pH}$ values

- Mixtures of acetic and butyric acids allow efficient hexanoic acid production

- Ethanol, acetic and/or butyric acids from syngas fermentation are suitable for chain elongation

BACKGROUND: The most common electron donor and electron acceptor for the production of hexanoic acid through chain elongation are ethanol and acetic acid, although they are not the only suitable ones. Acetic acid, and sometimes ethanol, can be obtained through different bioconversion processes such as the anaerobic digestion of solid waste (Chen et al., 2017), wastewater (Wu et al., 2018), or other feedstocks. The presence of other metabolites is not unusual, while some ethanol may need to be added if its concentration is limiting. Alternatively, the acetogenic bioconversion of syngas, as well as industrial emissions containing $\mathrm{C}_{1}$ gases, such as $\mathrm{CO}$ and $\mathrm{CO}_{2}$, will also yield acetic acid as an end metabolite. A limited number of anaerobic bacteria can also produce ethanol from $C_{1}$ gases, besides acetic acid (van Groenestijn et al., 2013). Occasionally, it has been observed that butyric acid and even some hexanoic acid may also be obtained directly from $\mathrm{C}_{1}$ gas fermentation by enriched anaerobic sludge (Chakraborty et al., 2019) or by some pure acetogenic bacteria (Fernández-Naveira et al., 2017a). Optimizing aspects such as the pH of the medium (FernándezNaveira et al., 2017b), the composition of the fermentation broth or the nature and concentration of trace metals (Fernández-Naveira et al., 2019) allows to select for the preferred end metabolites. Volatile fatty acids (VFA) such as butyric acid may thus be present, besides acetic acid, in such type of primary gas fermentation process, depending on aspects such as the nature of the biocatalyst, the $\mathrm{pH}$, or the composition of the culture broth. Therefore, it is worth evaluating the effect of both acetic acid and butyric acid, individually or in mixture, as electron acceptors, as well as the effect of the composition of the culture medium and its $\mathrm{pH}$, on chain elongation. Few recent studies have reported about the possibility to combine syngas fermentation with chain elongation (Gildemyn et al., 2017), and it is thus also worth to study the effect of such parameters in integrated syngas fermentation and chain elongation processes. Therefore, the afore mentioned goals were the main objectives of the present research. 
RESULTS \& DISCUSSION: A first set of experiments was performed in automated suspended-growth bioreactors, under mesophilic conditions, with constant $\mathrm{pH}$ adjustment. With ethanol as electron donor, either acetic acid or butyric acid, individually, or their mixtures, all allowed the production of hexanoic acid through chain elongation with Clostridium kluyveri, using similar molar alcohol/acid ratios around 3.5 in all cases and initial ethanol concentrations around $15 \mathrm{~g} / \mathrm{L}$. However, the efficiencies in terms of growth rates and bioconversion were the highest with the mixture of acids and they were the lowest with pure butyric acid as single VFA. Typical growth rates of $0.039 \mathrm{~h}^{-1}$ were found with the mixture of VFA, while it dropped to $0.010 \mathrm{~h}^{-1}$ with butyric acid as single electron acceptor. There was no large difference between pure acetic acid $\left(\mu_{\max }=0.031 \mathrm{~h}^{-1}\right)$ and the mixture of VFA though. On the other hand, increasing the initial available amount of electron donor (ethanol) to $25 \mathrm{~g} / \mathrm{L}$, while maintaining the same initial concentrations of VFA, did not improve the process and basically similar maximum concentrations of hexanoic acid, of about $18 \mathrm{~g} / \mathrm{L}$, were obtained at each initial ethanol concentration; simply a larger unused amount of electron donor remained in the medium at the end of the process when its concentration was initially higher. Besides, near neutral $\mathrm{pH}$ values were optimal compared to slightly acidic or basic conditions. Slightly acidic conditions (e.g., $\mathrm{pH}=6.4$ ) had a clear negative effect on bacterial growth and chain elongation with $C$. kluyveri. Instead, regulating the $\mathrm{pH}$ with an inorganic carbon source such as $\mathrm{NaHCO}_{3}$, rather than simply using $\mathrm{HCl} / \mathrm{NaOH}$, had a somewhat positive effect on that chain elongation process. On the other hand, poorer culture media, e.g. without yeast extract, led to lower concentrations of end product, compared to reacher media.

A second set of, still on-going, experiments was setup in order to evaluate the bioconversion of syngas fermented media containing different ratios of acids and alcohols, at different $\mathrm{pH}$ values, showing the feasibility of such approach and reaching different efficiencies, depending on the characteristics of each fermented medium. Either mixed cultures (Angenent et al., 2016) or pure cultures (San Valero et al., 2020) can be used for chain elongation. A pure culture of $C$. kluyveri was used in the present study. Since $C_{1}$ gas fermenting acetogens are better producers of acids than alcohols, it appeared that the addition of exogenous ethanol may, occasionally, be useful or even necessary in order to ensure chain elongation at suitable alcohol/acid ratios. Besides, maintaining a near neutral, constant, $\mathrm{pH}$ value of the syngas fermented broth around 6.8 is useful for an optimal bioconversion process.

CONCLUSIONS: Chain elongation in C. kluyveri is most efficient with mixtures of both acetic and butyric acids as electron acceptors, with optimal conditions at near neutral $\mathrm{pH}$ and in a rich medium. Syngas fermented broth, containing any or both of those acids can then efficiently be used for chain elongation. A limited number of cultures will also generate ethanol from syngas fermentation, although its concentration may need to be adjusted, i.e. increased, in order to reach the required alcohol/acid ratios. 
ACKNOWLEDGEMENTS: This research was partly funded through project CTQ2017-88292-R (MINECO). The BIOENGIN group at University of La Coruña is recognized and funded by Xunta de Galicia as Competitive Reference Research Group (GRC) (ED431C-2017/66).

\section{REFERENCES}

1. Angenent, L.T., Richter, H., Buckel, W., Spirito, C.M., Steinbusch, K.J.J., Plugge, C.M., Strik, D.P.B.T.B., Grootscholten, T.I.M., Buisman, C.J.N., Hamelers, H.V.M., 2016. Chain elongation with reactor microbiomes: Open-culture biotechnology to produce biochemicals. Environ. Sci. Technol. 50:2796-2810.

2. Chakraborty, S., Rene, E.R.R., Lens, P.N.L., Veiga, M.C., Kennes, C., 2019. Enrichment of a solventogenic anaerobic sludge converting carbon monoxide and syngas into acids and alcohols. Bioresour. Technol. 272:130136.

3. Chen, W.-S., Strik, D.P.B.T.B., Buisman, C.J.N., Kroeze, C., 2017. Production of caproic acid from mixed organic waste: an environmental life cycle perspective. Environ. Sci. Technol. 51:7159-7168.

4. Fernández-Naveira, Á., Abubackar, H.N., Veiga, M.C., Kennes, C., 2017a. Production of chemicals from $\mathrm{C}_{1}$ gases $\left(\mathrm{CO}, \mathrm{CO}_{2}\right)$ by Clostridium carboxidivorans. World J. Microbiol. Biotechnol. 33:43.

5. Fernández-Naveira, Á., Veiga, M.C., Kennes, C., 2017b. Effect of pH control on the anaerobic $\mathrm{H}-\mathrm{B}-\mathrm{E}$ fermentation of syngas in bioreactors. J. Chem. Technol. Biotechnol. 92:1178-1185.

6. Fernández-Naveira, Á., Veiga, M.C., Kennes, C., 2019. Selective anaerobic fermentation of syngas into either $\mathrm{C}_{2}-\mathrm{C}_{6}$ organic acids or ethanol and higher alcohols. Bioresour. Technol. 280:387-395.

7. van Groenestijn, J.W., Abubackar, H.N., Veiga, M.C., Kennes, C., 2013. Bioethanol (Chapter 18) In: Kennes, C. and Veiga, M.C. (Eds), Air Pollution Prevention and Control: Bioreactors and Bioenergy. John Wiley \& Sons, Chichester, UK, pp. 431-463. ISBN 978-1-1199-4331-0.

8. Gildemyn, S., Molitor, B., Usack, J.G., Nguyen, M., Rabaey, K., Angenent, L.T., 2017. Up-grading syngas fermentation effluent using Clostridium kluyveri in a continuous fermentation. Biotechnol. Biofuels 10, 83.

9. San Valero, P., Abubackar, H.N., Veiga, M.C., Kennes, C., 2020. Effect of $\mathrm{pH}$, yeast extract, and inorganic carbon on chain elongation for hexanoic acid production. Bioresour. Technol. 300:122659.

10. Wu, Q., Guo, W., Bao, X., Meng, X., Yin, R., Du, J., Zheng, H., Feng, X., Luo, H., Ren, N. 2018. Upgrading liquor-making wastewater into medium chain fatty acid: Insights into co-electron donors, key microflora and energy harvest. Water Res. 145:650-659. 